\title{
Limit of Superheat of Polystyrene-Cyclohexane Solutions: Theory
}

\author{
John H. Jennings \\ Jennings Research \& Editing \\ 2530 Hillegass Ave. \#307, Berkeley, CA 94704 \\ Email: jhjennings@juno.com
}

\begin{abstract}
A theory for the surface tension of polymer solutions is used along with classical nucleation theory to predict the temperature rise above the solvent limit of superheat due to addition of polymer. Polystyrene, of 2000, 4000, 50,000 and 100,000 molecular weight, was added to cyclohexane and it produced a linear rise in the superheat near weight fraction $=0$ to an extent that depends upon both molecular weight and concentration. So far, there has been limited progress in understanding homogeneous nucleation in polymer solutions from a theoretical standpoint. The theory presented here is used in the athermal case $(\mathrm{dT}=0)$ to give the temperature rise with respect to weight fraction, which is inversely proportional to the molecular weight of the polymer, and the agreement with the data is rather good.
\end{abstract}

Keywords: Polymer solutions; nucleation; surface thermodynamics; limit of superheat.

\section{Aims and scope}

When a liquid is heated in its pure condition, it is possible to raise the temperature to about 0.89 of its critical point in degrees Kelvin, well above its boiling point for one atmosphere, and then it explosively vaporizes. Classical nucleation theory (Frenkel, 1955) predicts this, and there are many liquids (Blander and Katz, 1975) that show this effect. Early work on the surface tension for polymer solutions was by Prigogine and Marechal (1952).

There are a number of groups that have gathered data concerning bubble nucleation in polymer solutions. Han and Han I (1990) used laser light scattering for polystyrene in toluene, and then did a theoretical study to analyze the results, Han and Han II (1990). Also, Kim, et al (2004) solve a molecular cluster model to predict bubble nucleation in polymer solutions among other things. Guo, et al (2012) have looked at $\mathrm{CO}_{2}$ bubble nucleation in polystyrene and modeled it using an extension of diffuse interface theory, but they remark that classical nucleation theory is most successful for quantifying the process of nucleation and that limited progress has been made on this topic. Devolatilization of different kinds of polymer melts was studied by Yarin, et al (1999) for homogeneous nucleation and they said that the bubble growth is controlled by momentum transfer and diffusion.

These treatments are complicated and I opt here to have a simple model, which looks at the bulk quantities and appears to predict homogeneous nucleation for polymer solutions in general. It would seem that companies processing polymer solutions and those studying nucleation theory would show interest, because this theory predicts the temperature rise fairly accurately and gives the proper trend for high molecular weight polymer.

\section{Measurements}

Jennings and Middleman (1985) collected data on this phenomenon for polystyrene-cyclohexane solutions of molecular weight 2000 to 100,000 for the polymer. There are various figures in their paper (see Appendix for polymer solution data). In Figure 1, there appears the linear rise in superheat for Pentane with addition of cyclohexane, by mass fraction. Figure 2 shows the same linear effect with addition of styrene monomer, MW=2000 polystyrene and $\mathrm{MW}=4000$ polystyrene. Figure 3 shows the same effect for $\mathrm{MW}=50,000$ and 100,000 and the initial rise is small, so it was felt that the additional steeper rise was due to the effect known as LCST or lower critical solution temperature; this was noted in Jennings and Middleman. There is some data for polystyrene/benzene solutions of various molecular weights that was gathered by Prud'homme and Gregory (1985) using a similar apparatus to Jennings and Middleman. The data from Prud'homme and Gregory do not show a very straight linear rise of temperature with respect to molecular weight and at high molecular weight the temperature of nucleation drops off to a considerable degree, so their data cannot be compared with the final equation in this paper.

\section{Theory}

According to Blander and Katz there is the following expression for the rate of nucleation $\mathbf{J}$ (number of bubbles formed per $\mathrm{cm}^{3}$ per second).

$$
\begin{aligned}
\mathrm{J} \approx & 3.73\left(10^{35}\right)\left[\mathrm{d}^{2} \sigma / \mathrm{M}^{3} \mathrm{~B}\right]^{1 / 2} \exp \left[-1.182\left(10^{5}\right) \sigma^{3}\right. \\
& \left./\left(\mathrm{T}\left(\mathrm{P}_{\mathrm{V}}-\mathrm{P}_{\mathrm{L}}\right)^{2}\right)\right]
\end{aligned}
$$

$\mathrm{d}$ is the liquid density, $\sigma$ is the surface tension, $\mathrm{M}$ is the molecular weight of solvent, $\mathrm{B}$ is a correction factor (equation (6) below), $\mathrm{T}$ is the temperature in degrees Kelvin, $P_{V}$ is the vapor pressure of the escaping gas molecules and $\mathrm{P}_{\mathrm{L}}$ is the hydrostatic pressure on the droplet of solution.

The polymer is non-volatile and the "bubble surface gains or loses molecules" of molecular weight $\mathrm{M}$ (Blander and Katz). At a certain value of $\mathbf{J}$ nucleation takes place at the limit of superheat $T_{1}$ and we would expect $\mathrm{J}$ to be equal 
among the four molecular weights of polymer as the concentration of polymer approaches zero. This treatment proves that only what happens on the surface of the nucleating bubble matters. Blander and Katz say there is a Poynting correction factor $\delta$ that relates the vapor pressure of the superheated liquid, $\mathrm{P}_{\mathrm{V}}$, to the equilibrium vapor pressure, $\mathrm{Pe}$, for small values of $\mathrm{P}_{\mathrm{L}}$, which is in this case atmospheric pressure. For this system, $\mathrm{Pe}=17.433 \mathrm{~atm}$ and $\mathrm{P}_{\mathrm{L}}=1 \mathrm{~atm}$, so this is satisfied, as $\mathrm{P}_{\mathrm{L}} / \mathrm{Pe}=0.057$. The Poynting correction factor is $\delta$.

$\delta=\left(\mathrm{P}_{\mathrm{V}}-\mathrm{P}_{\mathrm{L}}\right) /\left(\mathrm{Pe}-\mathrm{P}_{\mathrm{L}}\right)$

Assuming the gas is ideal in the equation,

$\mathrm{d}_{\mathrm{G}}=\mathrm{Pe} \mathrm{MW}_{1} / \mathrm{RT}_{1}$, and

$$
\begin{aligned}
\delta & \approx 1-\mathrm{V}_{\mathrm{L}} / \mathrm{Ve}+1 / 2\left(\mathrm{~V}_{\mathrm{L}} / \mathrm{Ve}\right)^{2} \\
& =1-\mathrm{d}_{\mathrm{G}} / \mathrm{d}+0.5\left(\mathrm{~d}_{\mathrm{G}} / \mathrm{d}\right)^{2}
\end{aligned}
$$

where the volumes and densities are for the liquid and gas in equilibrium. Blander and Katz give a proof for equation (3) and say it is generally accurate up to one atmosphere pressure, the condition in which the data was collected by Jennings and Middleman.

When considering bubble nucleation for polymer solutions it seems that one should only look at the surface layer from which the solvent molecules are either escaping or adhering. Accordingly, the density would be the volume fraction weighted sum at the surface of the respective densities and the equilibrium vapor pressure would be directly proportional to the volume fraction of solvent at the surface. In polymer solutions, nucleation depends only on what is happening near the surface, so the density is essentially the density of the solvent and the equilibrium vapor pressure follows Raoult's Law.

$\mathrm{d}=\mathrm{d}_{1} \varphi_{1 \mathrm{~S}}+\mathrm{d}_{2} \varphi_{2 \mathrm{~S}}=\mathrm{d}_{1}+\left(\mathrm{d}_{2}-\mathrm{d}_{1}\right) \varphi_{2 \mathrm{~S}}$

$\operatorname{Pe}=\operatorname{Pe}(0) \varphi_{1 S}=\operatorname{Pe}(0)\left(1-\varphi_{2 S}\right)$

$\varphi_{1 \mathrm{~S}}$ and $\varphi_{1}$ and are the surface and interior volume fractions of solvent (the subscript 2 refers to the polymer). This is because the surface is the only thing the nucleating bubble "sees" and the rest of the interior could be regarded as having the same concentration as the surface. According to calculations made by Siow and Patterson (1973), for preferential solvent adsorption, $\sigma_{2}>\sigma_{1}$, the adsorption isotherm (in their Fig. 1) hardly changes with molecular weight above molecular weight 2500 , so the surface volume fraction of polymer is essentially zero all the way up to $\varphi_{2}=$ 0.3 . When $\sigma_{2}-\sigma_{1} \approx 22 \mathrm{dyne} / \mathrm{cm}$ there obtains preferential solvent adsorption, so in that case "there is little qualitative difference between the surface thermodynamics of a polymer solution and a mixture of spherical molecules". (The data that Jennings and Middleman gathered was only up to about weight fraction 0.3 and above that for high MW it was felt that the LCST phenomenon took over.) Below in Eq. (10) this is made quantitative.

In the equation for $\mathbf{J}=\mathrm{A} \exp (\mathrm{K})$ there is also a correction factor $\mathrm{B}$ which has little effect on the limit of superheat because for $\mathrm{J}$ large errors in the prefactor A "lead to very small errors in predictions of the superheats needed to cause homogeneous nucleation" (Blander and Katz).

$\mathrm{B} \approx 1-1 / 3\left(1-\mathrm{P}_{\mathrm{L}} / \mathrm{P}_{\mathrm{V}}\right)$
The B factor accounts for the fact that the bubble is in mechanical equilibrium, is close to $2 / 3$, and for the purposes of its calculation, $\mathrm{P}_{\mathrm{V}}=\mathrm{Pe}$, as it has a negligible effect on the temperature of nucleation. The $\delta$ correction factor is needed because the nucleating droplet is under pressure $\mathrm{P}_{\mathrm{L}}=1$ atm pressure (other than its equilibrium vapor pressure $\mathrm{Pe}$ ) and must be included as it is in the exponent. It will be seen later that $\delta$ and the equilibrium vapor pressure drop out of the calculation for these polymer solutions.

The following two equations apply for the athermal case $(\mathrm{dT}=0)$ by the theory of Siow and Patterson for polymer solutions, where $\mathrm{a}=$ surface area of the solvent molecule and $r=$ ratio of the molar volume of the polymer to that of the solvent. Eq. (7) gives the surface tension and Eq. (8) relates the surface and interior volume fractions.

$\left(\sigma-\sigma_{1}\right) \mathrm{a} / \mathrm{kT}=\ln \left(\varphi_{1 \mathrm{~S}} / \varphi_{1}\right)+((\mathrm{r}-1) / \mathrm{r})\left(\varphi_{2 \mathrm{~S}}-\varphi_{2}\right)$

$\ln \left[\left(\varphi_{2 \mathrm{~S}} / \varphi_{2}\right)^{1 / \mathrm{r}} /\left(\varphi_{1 \mathrm{~S}} / \varphi_{1}\right)\right]=\left(\sigma_{1}-\sigma_{2}\right) \mathrm{a} / \mathrm{kT}$

Near $\varphi_{2}=0$, Eq. (7) becomes

$\partial \sigma / \partial \varphi_{2}=\mathrm{kT} / \mathrm{ra}$

Near $\varphi_{2}=0$, Eq. (8) becomes

$\varphi_{2 S}=\varphi_{2} \exp \left[\mathrm{r}\left(\sigma_{1}-\sigma_{2}\right) \mathrm{a} / \mathrm{kT}\right]$

Putting in the numbers, $\partial \varphi_{2 S} / \partial \varphi_{2} \approx 10^{-38}$ (for MW $=2000, \mathrm{r}$ $=13.4$ ) and even less for higher MW. Thus, polymer is present in vanishingly small volume fraction in the surface for $w_{2} \leq 0.3$ for which there is data. That is why the density and vapor pressure only apply to what is at the surface. The gas molecules escape or adhere to the surface of a bubble nucleating in the interior of the rising droplet of solution.

So, the following equations are true: $\partial \delta / \partial \varphi_{2}=0, \partial \mathrm{d} / \partial \varphi_{2}$ $=0, \partial \mathrm{Pe} / \partial \varphi_{2}=0$, and $\partial \mathrm{B} / \partial \varphi_{2}=0$ for $\mathrm{w}_{2}$ near 0 . The rate of nucleation is of the form $\mathrm{J}=\mathrm{A} \exp (\mathrm{K})$ and $\left(\partial \ln \mathrm{A} / \partial \mathrm{w}_{2}\right) /\left(\partial \mathrm{K} / \partial \mathrm{w}_{2}\right)$ and $(\partial \ln \mathrm{A} / \partial \mathrm{T}) /(\partial \mathrm{K} / \partial \mathrm{T})$ are both small near the origin $\left(0, \mathrm{~T}_{1}\right)$. It turns out that they both are about $0.2 \%$ and that establishes for any ray emanating from the origin, $\Delta \mathrm{J}=\mathrm{J} \Delta \mathrm{K}$, so $\Delta \mathrm{J}=0 \rightarrow \Delta \mathrm{K}=0$. Therefore $\mathrm{K}$ can be taken as a constant where the 2000, 4000, 50,000 and 100,000 curves meet. An expression for $\partial \mathrm{T} / \partial \mathrm{w}_{2}$ can be derived from the fact that $\mathrm{K}$ dominates in nucleation and that is done in this theory.

For the weight fraction, this ratio is independent of the molecular weights and surface area of the solvent molecule. It is simply:

$\lim \mathrm{w}_{2} \rightarrow 0\left(\partial \ln \mathrm{A} / \partial \mathrm{w}_{2}\right) /\left(\partial \mathrm{K} / \partial \mathrm{w}_{2}\right)=1 /(6 \mathrm{~K})=-0.24 \%$

In the temperature direction, there are a number of terms, as each parameter depends on temperature. These expressions are for $\mathrm{T} \rightarrow \mathrm{T}_{1}$. See Appendix for values of parameters and partial derivatives.

$$
\begin{aligned}
& \partial \ln \mathrm{A} / \partial \mathrm{T}=\left(\partial \mathrm{d}_{1} / \partial \mathrm{T}\right) / \mathrm{d}_{1}+0.5(\partial \sigma / \partial \mathrm{T}) / \sigma \\
& -0.5(\partial \mathrm{B} / \partial \mathrm{T}) / \mathrm{B}=-0.01251 \\
& \partial \mathrm{K} / \partial \mathrm{T}=-1.182 \times 10^{5}\left[3 \sigma^{2}(\partial \sigma / \partial \mathrm{T}) /\left(\mathrm{T} \delta^{2}\left(\mathrm{Pe}-\mathrm{P}_{\mathrm{L}}\right)^{2}\right)\right. \\
& -\sigma^{3} /\left(\mathrm{T}^{2} \delta^{2}\left(\mathrm{Pe}-\mathrm{P}_{\mathrm{L}}\right)^{2}\right)-2 \sigma^{3}(\partial \delta / \partial \mathrm{T}) /\left(\mathrm{T} \delta^{3}\left(\mathrm{Pe}-\mathrm{P}_{\mathrm{L}}\right)^{2}\right) \\
& \left.-\left(2 \sigma^{3} /\left(\mathrm{T} \delta^{2}\left(\mathrm{Pe}-\mathrm{P}_{\mathrm{L}}\right)^{3}\right)\right)(\partial \mathrm{Pe} / \partial \mathrm{T})\right]=6.488
\end{aligned}
$$


$\lim \mathrm{T} \rightarrow \mathrm{T}_{1}(\partial \ln \mathrm{A} / \partial \mathrm{T}) /(\partial \mathrm{K} / \partial \mathrm{T})=-0.19 \%$

The reason these two ratios do not agree exactly must be mainly in the estimation for the surface tension. It is extrapolated far beyond the data up near the critical point. The pressure is close, except the Poynting correction may be off a bit. Otherwise, the approximation that $\mathrm{K}=$ const. is good, so it would hold for all the data.

Neglecting the change in the coefficient one can easily derive an expression for $\lim \varphi_{2} \rightarrow 0$ for $\partial \mathrm{T} / \partial \varphi_{2}$ where $\varphi_{2}$ is the volume fraction of polymer in the interior of the droplet. The exponent is then taken constant.

$\mathrm{K}=-1.182 \times 10^{5} \sigma^{3} / \mathrm{T}\left(\mathrm{P}_{\mathrm{V}}-\mathrm{P}_{\mathrm{L}}\right)^{2}$

So, solving for $\mathrm{T}$, then differentiating (using partial derivatives throughout this paper).

$\lim \varphi_{2} \rightarrow 0 \partial \mathrm{T} / \partial \varphi_{2}=\mathrm{T}_{1}\left(\left(3 / \sigma_{1}\right) \partial \sigma / \partial \varphi_{2}\right.$

$$
\left.-\left(2 /\left(\mathrm{P}_{\mathrm{V}}-\mathrm{P}_{\mathrm{L}}\right)\right) \partial \mathrm{P}_{\mathrm{V}} / \partial \varphi_{2}\right)
$$

In Siow and Patterson's theory for polymer solutions, the surface volume of solvent and interior volume of solvent are used here in the simple athermal $(\mathrm{dT}=0)$ case. Their theory is for the surface tension of a polymer solution against a liquid and in the experimental conditions the droplet rose in a column of heated glycerol where the temperature rises as the droplet ascends in the column. This surface tension is taken to be the surface tension of the nucleating bubble within the droplet. Substituting (2) into (14) and using the fact that $\partial \delta / \partial \varphi_{2}=0$ for $w_{2}$ near 0

$$
\begin{aligned}
& \lim \varphi_{2} \rightarrow 0 \partial \mathrm{T} / \partial \varphi_{2}=\mathrm{T}_{1}\left(\left(3 / \sigma_{1}\right) \partial \sigma / \partial \varphi_{2}\right. \\
& \left.\quad-\left(2 /\left(\mathrm{Pe}-\mathrm{P}_{\mathrm{L}}\right)\right) \partial \mathrm{Pe} / \partial \varphi_{2}\right)
\end{aligned}
$$

The result (using (9) and (15)) along with the fact that $\partial \mathrm{Pe} / \partial \varphi_{2}=0$ near $\varphi_{2}=0$ is:

$\lim \varphi_{2} \rightarrow 0 \quad \partial \mathrm{T} / \partial \varphi_{2}=3 \mathrm{k} \mathrm{T}_{1}^{2} / \sigma_{1} \mathrm{ra}$

where $\mathrm{k}=$ Boltzmann constant, $\mathrm{T}_{1}=$ limit of superheat of cyclohexane, $\sigma_{1}=$ surface tension of cyclohexane at $T_{1}, r=$ ratio of molar volume of polymer to molar volume of solvent at $\mathrm{T}_{1}$ and $\mathrm{a}=$ surface area of the solvent molecule at $\mathrm{T}_{1}$.

One adjustment made to Siow and Patterson was in the calculation of the surface area of the cyclohexane molecule, according to the formulas for a sphere

$\mathrm{a}=\left(4 \pi /(4 \pi / 3)^{2 / 3}\right) \mathrm{V}^{2 / 3}=4.836 \mathrm{~V}^{2 / 3}$

where $\mathrm{V}$ is the molar volume of cyclohexane at $\mathrm{T}_{1}$ divided by Avogadro's number, $\mathrm{N}_{\mathrm{o}}, 6.0225 \times 10^{23}$ molecules $/$ mole.

The data for surface tensions of cyclohexane (Jasper, 1972) (extrapolated) and polystyrene (Wu, 1970), the densities for cyclohexane (Kerimov and Apaev, 1972) (extrapolated) and polystyrene (Bernardo and Vesely, 2007), and the vapor pressure of cyclohexane (CRC, 44th) were taken from the indicated sources. The polystyrene (Mukherji and Ahuja, 1981) was from Pressure Chemical Co. (erratum in Jennings and Middleman). Density data for cyclohexane was from the Internet by (DDBST). See Appendix for details on data calculations.

\section{Results}

Following is a table comparing theory with experiment. In this simplified equation, all quantities are at the limit of superheat for the solvent.

$\lim _{\mathrm{w}_{2}} \rightarrow 0 \partial \mathrm{T} / \partial \mathrm{w}_{2}=\left(\mathrm{MW}_{1} / \mathrm{MW}_{2}\right)\left(3 \mathrm{kT}_{1}^{2} / \sigma_{1} \mathrm{a}\right)$

\begin{tabular}{|c|c|c|c|c|}
\hline $\begin{array}{l}\text { Molecular } \\
\text { weight }\end{array}$ & 2000 & 4000 & 50,000 & 100,000 \\
\hline $\begin{array}{ll}\partial \mathrm{T} / \partial \mathrm{w}_{2} & \mathrm{~T} \text { in } \\
{ }^{\circ} \mathrm{C} & \end{array}$ & & & & \\
\hline Theory & 52.58 & 26.29 & 2.10 & 1.05 \\
\hline Experiment & 48.48 & 28.78 & 3.62 & 2.66 \\
\hline $\begin{array}{l}\Delta \mathrm{T} \text { in }{ }^{\circ} \mathrm{C} \text { for } \\
\mathrm{w}_{2}=0.2\end{array}$ & +0.82 & -0.50 & -0.30 & -0.32 \\
\hline
\end{tabular}

Table 1. Theory vs. experiment for polystyrene in cyclohexane.

Eq. (18) does reasonably well at predicting the limit of superheat for all the data. The average deviation in the slope for the two lower MWs is about $8 \%$, but since the temperature rise is only about $10-15{ }^{\circ} \mathrm{C}$ at 30 weight percent, if the athermal slope is used, the prediction gives an error of 0.5 or $0.8{ }^{\circ} \mathrm{C}$ at $20 \%$ weight fraction between theory and experiment. Notice that as the MW of polymer grows large, the temperature rise from this phenomenon is much less; that is what is found for the data in Jennings and Middleman for low weight fraction and higher molecular weight. However, the slope is more accurate at low molecular weight.

\section{Conclusions}

The athermal version of a theory for surface thermodynamics of polymer solutions by Siow and Patterson is used along with classical nucleation theory to predict the limit of superheat of polystyrene-cyclohexane solutions from 2000 to 100,000 molecular weight at one atmosphere pressure collected by Jennings and Middleman. Eq. (18) fairly well predicts the limit of superheat for all the data. However, the slope is more accurate at low molecular weight. As the molecular weight of polymer grows large, the temperature rise from this phenomenon is much less.

\section{Acknowledgements}

This paper is dedicated to the memory of my father, Percy H. Jennings, Jr. Also, thanks are given to Abigail T. Neidleman for rekindling my interest in science.

\section{Nomenclature (see Appendix for units)}

a surface area of solvent molecule

B factor $\approx 2 / 3$

d density of liquid

$\mathrm{d}_{\mathrm{i}} \quad$ density of solvent (1) or polymer (2)

$\mathrm{d}_{\mathrm{G}} \quad$ density of gas at equilibrium vapor pressure

$\mathrm{k}$ Boltzmann constant

M molecular weight of solvent molecule

$\mathrm{MW}_{\mathrm{i}}$ molecular weight of solvent or polymer

$\mathrm{N}_{\mathrm{o}}$ Avogadro's number

$\mathrm{Pe}$ equilibrium vapor pressure of gas in bubble

$\mathrm{P}_{\mathrm{L}} \quad$ ambient pressure on solution droplet

$\mathrm{P}_{\mathrm{V}} \quad$ vapor pressure of gas in bubble

$r$ ratio of molar volume of polymer to molar volume of solvent

$\mathrm{T}_{1}$ temperature of limit of superheat for pure solvent at 1 atm 
$\mathrm{V}_{\mathrm{i}}$ molar volume of solvent (L) or vapor (e) in equilibrium

$\mathrm{w}_{2} \quad$ weight fraction polymer

$\delta \quad$ Poynting correction factor

$\sigma_{1} \quad$ surface tension of solvent

$\sigma_{2} \quad$ surface tension of polymer

$\varphi_{\mathrm{i}} \quad$ volume fraction of solvent or polymer in interior of solution

$\varphi_{\text {is }}$ volume fraction of solvent or polymer on surface of solution

APPENDIX - Data for calculations of temperature rise in superheat

\section{DATA PERTAINING TO EQUATION (18)}

$\mathrm{MW}_{1}=84.161 \quad \mathrm{MW}_{2}=2000-100,000$

$\sigma_{1}=4.0904 \mathrm{dyne} / \mathrm{cm} \quad \sigma_{2}=26.329 \mathrm{dyne} / \mathrm{cm}$

$\mathrm{T}_{1}=492.75 \mathrm{~K} \quad \mathrm{~d}_{1}=0.5386 \mathrm{~g} / \mathrm{cc} \quad \mathrm{a}=196.73 \times 10^{-16} \mathrm{~cm}^{2}$

$\mathrm{k}=1.3805 \times 10^{-16} \mathrm{erg} / \mathrm{deg}$

1. Formulas for $\sigma, P e, d, \delta$ for pure cyclohexane $T_{l}=$ 492.75 Kelvin

$\sigma_{1}=60.8402(1-\mathrm{T} / 553.55)^{11 / 9} \quad$ dyne-cm $\quad($ Jasper $)$

$\mathrm{B}=0.6858$

$\mathrm{R}=82.056 \mathrm{~cm}^{3} \mathrm{~atm} \mathrm{deg}^{-1} \mathrm{~mole}^{-1}$

$\mathrm{MW}_{1}=84.161$ (cyclohexane)

$\mathrm{Pe}=0.0079473 \exp (0.015613 \mathrm{~T})$ atm

(CRC, 44th ed.)

$\delta=1-\mathrm{d}_{\mathrm{G}} / \mathrm{d}_{1}+0.5\left(\mathrm{~d}_{\mathrm{G}} / \mathrm{d}_{1}\right)^{2}=0.9349$

(Blander and Katz)

$\mathrm{d}_{\mathrm{G}}=(\mathrm{Pe} / \mathrm{RT}) \mathrm{MW}_{1}=0.03629 \mathrm{~g} / \mathrm{cc}$

ideal gas in equilibrium with liquid

$\mathrm{d}_{1}=0.587326 \mathrm{~g} / \mathrm{cc}$ at 465.32 Kelvin

and $0.576276 \mathrm{~g} / \mathrm{cc}$ at 473 Kelvin

$=1.2568-0.0014388 \mathrm{~T}$

(DDBST)

2. Data at limit of superheat of cyclohexane

$\mathrm{d}_{1}=0.5386 \mathrm{~g} / \mathrm{cc} \quad \mathrm{d}_{2}=0.9571 \mathrm{~g} / \mathrm{cc}$

$\sigma_{1}=4.0904$ dyne $/ \mathrm{cm} \sigma_{2}=26.329 \mathrm{dyne} / \mathrm{cm}$

$\mathrm{Pe}=17.433 \mathrm{~atm} \quad \mathrm{P}_{\mathrm{L}}=1 \mathrm{~atm}$

3. Need to calculate partial derivatives at $T_{l}=492.75$ Kelvin

$\partial \sigma_{1} / \partial \mathrm{T}=-0.1343\left(1-\mathrm{T}_{1} / 553.55\right)^{2 / 9}=-0.08223$

$\partial \mathrm{Pe} / \partial \mathrm{T}=0.00012408 \exp \left(0.015613 \mathrm{~T}_{\mathrm{l}}\right)=0.2722$

$\partial \delta / \partial \mathrm{T}=-\left((\partial \mathrm{Pe} / \partial \mathrm{T}) \mathrm{MW}_{1} /\left(\mathrm{RT} \mathrm{d}_{1}\right)-\mathrm{PeMW}_{1} /\left(\mathrm{RT}^{2} \mathrm{~d}_{1}\right)-\right.$

$\left.\left(\operatorname{Pe~} \mathrm{MW}_{1} /\left(\mathrm{RT}\left(\mathrm{d}_{1}\right)^{2}\right)\right)\left(\partial \mathrm{d}_{1} / \partial \mathrm{T}\right)\right)\left(1-\mathrm{d}_{\mathrm{G}} / \mathrm{d}_{1}\right)$

$=-0.001021$

$\partial \mathrm{d}_{1} / \partial \mathrm{T}=-0.001439$

$\partial \mathrm{B} / \partial \mathrm{T}=-(1 / 3) \mathrm{P}_{\mathrm{L}} /(\mathrm{Pe})^{2}(\partial \mathrm{Pe} / \partial \mathrm{T})=-0.0002986$

$\left(\mathrm{P}_{\mathrm{V}}\right.$ is approximated as Pe because this is small)
4. Polystyrene in cyclohexane: data are from UCSD Research Summary Jan. 11, 1983 (Jennings and Middleman, MACROMOLECULES Vol. 18, No. 11, 1985).

$\mathrm{MW}=2000$

$\mathrm{X}=$ wt fract. PS

0

0.036

$\mathrm{Y}=\mathrm{T}$ degrees Centigrade

219.6

221.35

$0.036 \quad 222$

$0.0825 \quad 223.4$

$0.0825 \quad 223.7$

$0.180 \quad 228.2$

$0.180 \quad 228.4$

$0.302 \quad 234.2$

$0.302 \quad 234.65$

Deg Centigrade $=219.697+(48.484)($ weight fraction polystyrene), $\mathrm{r}=0.999$

$\mathrm{MW}=4000$

$\mathrm{X}=$ wt fract. $\mathrm{PS} \quad \mathrm{Y}=\mathrm{T}$ degrees Centigrade

$0 \quad 219.6$

$0.03 \quad 220.2$

$0.03 \quad 220.7$

$0.044 \quad 220.4$

$0.043 \quad 220.7$

$0.092 \quad 222.1$

$0.091 \quad 222.3$

$0.095 \quad 221.55$

$0.095 \quad 221.7$

$0.137 \quad 223.7$

$0.142 \quad 223.1$

$0.211 \quad 225.8$

$0.210 \quad 225.95$

$0.219 \quad 225.5$

$0.219 \quad 225.95$

$0.230 \quad 226.2$

$0.230 \quad 226.9$

$0.288 \quad 227.0$

$0.288 \quad 228.05$

$0.311 \quad 227.55$

$0.310 \quad 228.7$

Deg Centigrade $=219.440+(28.779)($ weight fraction polystyrene), $r=0.99$

$\mathrm{MW}=50,000$

$\mathrm{X}=$ wt fract. PS $\mathrm{Y}=\mathrm{T}$ degrees Centigrade

$0 \quad 219.6$

$0.036 \quad 220.05$

$0.036 \quad 219.7$

$0.106 \quad 220.05$

$0.106 \quad 220.04$

Deg Centigrade $=219.682+(3.621)($ weight fraction polystyrene), $r=0.78$

$\mathrm{MW}=100,000$

$\mathrm{X}=$ wt fract. PS $\mathrm{Y}=\mathrm{T}$ degrees Centigrade

$0 \quad 219.2$

$\begin{array}{ll}0 & 219.7\end{array}$

$0.038 \quad 219.25$

$0.038 \quad 219.6$

$0.089 \quad 219.45$

$0.089 \quad 219.85$

$0.118 \quad 219.6$

$0.118 \quad 220.0$

$0.154 \quad 219.6$

$0.154 \quad 219.95$ 
Deg Centigrade $=219.408+(2.662)($ weight fraction polystyrene), $r=0.57$

\section{Density of cyclohexane (extrapolated)}

$\mathrm{d}_{1}=0.5386 \mathrm{~g} / \mathrm{cc}$ The following data are from Kerimov and Apaev (1972).

$\begin{array}{lcl}\mathrm{T}(\mathrm{K}) & \text { Pressure } & \text { Density }=\mathrm{d}_{1} \\ 283.15 & 101.300 \mathrm{kPa} & 0.7891 \mathrm{~g} / \mathrm{cc} \text { (laboratory pressure) } \\ 348.15 & 101.300 \mathrm{kPa} & 0.7265 \mathrm{~g} / \mathrm{cc} \\ & & \\ 283.15 & 1082.00 \mathrm{kPa} & 0.7900 \mathrm{~g} / \mathrm{cc} \\ 348.15 & 1082.00 \mathrm{kPa} & 0.7276 \mathrm{~g} / \mathrm{cc}\end{array}$

for $283.15 \mathrm{~K} \quad \Delta \mathrm{d}_{1} / \Delta \mathrm{kPa}=(0.79-0.7891) /(1082-101.3)=$ 0.00000091771

for $348.15 \mathrm{~K} \Delta \mathrm{d}_{1} / \Delta \mathrm{kPa}=(0.7276-0.7265) /(1082-101.3)=$ 0.00000112165

Extrapolating, get $\Delta \mathrm{d}_{1} / \Delta \mathrm{kPa}$ for $\mathrm{T}=492.75 \mathrm{~K}$ between the pressures.

$\Delta \mathrm{d}_{1} / \Delta \mathrm{kPa}=0.00000091771+((0.00000112165-$

$0.00000091771) /(348.15-283.15))(492.75-283.15)$

$=0.000001575$

Then, this is used to extrapolate the following data down to $760 \mathrm{mmHg}=101.3 \mathrm{kPa}$.

$\mathrm{T}(\mathrm{K}) \quad$ Pressure Density $=\mathrm{d}_{1}$

$473.15 \quad 1082.00 \mathrm{kPa} \quad 0.5788 \mathrm{~g} / \mathrm{cc}$

$498.15 \quad 1082.00 \mathrm{kPa} \quad 0.5295 \mathrm{~g} / \mathrm{cc}$

First, interpolate between the two temperatures for $\mathrm{T}=492.75 \mathrm{~K}$.

$\mathrm{d}_{1}(1082 \mathrm{kPa}, \quad 492.75 \mathrm{~K})=0.5788+((0.5295-$ $0.5788) /(498.15-473.15))(492.75-473.15)=0.54015 \mathrm{~g} / \mathrm{cc}$

Then, extrapolate between the pressures.

$\mathrm{d}_{1}(101.3 \mathrm{kPa}, 492.75 \mathrm{~K})=0.54015+(0.000001575)(101.3-$ $1082)=0.5386 \mathrm{~g} / \mathrm{cc}$

\section{Surface tension of cyclohexane (extrapolated)}

$\sigma_{1}=4.0904$ dyne/cm at $\mathrm{T}=492.75 \mathrm{~K}$

The following data are from Jasper (1972) - cyclohexane surface tension: dyne-cm $( \pm 0.01)$, $\mathrm{T}$ in degrees Centigrade. $40^{\circ} \quad 50^{\circ} \quad 60^{\circ} \quad 70^{\circ}$

$\begin{array}{llll}22.87 & 21.68 & 20.49 & 19.30\end{array}$

The well-known empirical formula for surface tension near the critical point is

$\sigma=\sigma_{\mathrm{o}}\left(1-\mathrm{T} / \mathrm{T}_{\mathrm{c}}\right)^{11 / 9}$ where $\mathrm{T}$ is in Kelvin

Values for $\sigma_{o}$ are calculated for $\mathrm{T}=40^{\circ}, 50^{\circ}, 60^{\circ}, 70^{\circ}$ Centigrade and then $\sigma_{\mathrm{o}}$ is extrapolated to $\mathrm{T}=219.6^{\circ} \mathrm{C}$, $\mathrm{T}_{\mathrm{c}}=553.55 \mathrm{~K}$.

$\sigma_{1}=60.8402(1-\mathrm{T} / 553.55)^{11 / 9}$

\section{References:}

Bernardo, G. and Vesely, D. (2007) Solubility of Carboxylic Acids in a Matrix of Uncross-Linked Polystyrene Eur Polym J. 43, 4983-4994.

Blander, M. and Katz, J.L. (1975) Bubble Nucleation in Liquids AIChE J. 21, 833-848.

CRC Handbook of Chemistry and Physics, 44th ed.

DDBST: Saturated Liquid Density www.ddbst.com/en/online/Online_Calc_den_Form.php ?component $=$ cyclohexaneDDBST Online Liquid Density Calculation. ... Select density from list: ... Chloroform, Cyclohexane, Diethyl ether, Ethanol, Ethyl acetate, Hexadecane, Isoprene ...

(Reference with data, found on Internet.)

Frenkel, J. (1955) Kinetic Theory of Liquids Dover, New York, Chapter 7.

Guo, Z., Burley, A.C., Koelling, K.W., Kusaka, I., Lee, L.J., and Tomasko, D.L. (2012) $\mathrm{CO}_{2}$ Bubble Nucleation in Polystyrene: Experimental and Modeling Studies $J$ Appl Polym Sci. 125, 2170-2186.

Han, J.H. and Han, C.D. (1990) Bubble Nucleation in Polymeric Liquids. I. Bubble Nucleation in Concentrated Polymer Solutions J Polym Sci Part B. 28, 711-741.

Han, J.H. and Han, C.D. (1990) Bubble Nucleation in Polymeric Liquids. II. Theoretical Considerations $J$ Polym Sci Part B. 28, 743-761.

Jasper, J.J. (1972) The Surface Tension of Pure Liquid Compounds J Phys Chem Ref Data. 1, 841-1009.

Jennings, J.H. and Middleman, S. (1985) Homogeneous Nucleation of Vapor from Polymer Solutions Macromol. 18, 2274-2276.

Kerimov, A. M. and Apaev, T.A. (1972) Teplofiz Svoistva Vesh Mater. 26-46. (Reference with data, found on Internet website below.)

DEN (Density) of Cyclohexane

ddbonline.ddbst.de/EE/50\%20DEN\%20(Density).shtml

Kim, K.I., Kang, S.L. and Kwak, H.Y. (2004) Bubble Nucleation and Growth in Polymer Solutions Poly Eng Sci. 44, 1890-1899.

Mukherji, A.K. and Ahuja, S.K. (1981) Dilute Solution Properties of Polystyrene, Polymethyl Methacrylate and their Random Copolymers J Macromol Sci-Chem. A15(2), 267-278.

Prigogine, I. and Marechal, J. (1952) The Influence of Differences in Molecular Size on the Surface Tension of Solutions IV J. Coll. Sci. 7, 122-127.

Prud'homme, R.K. and Gregory W.J. (1985) Homogeneous Nucleation Temperatures for Concentrated PolystyreneBenzene Solutions J Polym Sci Symp. 72, 263-275. 
Siow, K.S. and Patterson, D. (1973) Surface Thermodynamics of Polymer Solutions J Phys Chem. 77, 356-365.

$\mathrm{Wu}$, S. (1970) Surface and Interfacial Tensions of Polymer Melts. II. Poly(methyl methacrylate), Poly(n-butyl methacrylate), and Polystyrene J Phys Chem. 74, 632638.

Yarin, A.L., Lastochkin, D., Talmon, Y., and Tadmor, Z. (1999) Bubble Nucleation During Devolatilization of Polymer Melts AIChE J. 45, 2590-2605. 